\title{
Incentive Decision on Safety Investment of Supply Chain of Agricultural Products in "Agricultural Super-Docking”
}

\author{
Weiqin Tang, ${ }^{1}$ Weimin Tang, ${ }^{2}$ Changsheng Jiang, ${ }^{3}$ and Shan Lu ${ }^{1}$ \\ ${ }^{1}$ School of Information and Safety Engineering, Zhongnan University of Economics and Law, Wuhan 430073, China \\ ${ }^{2}$ School of Accounting, Zhongnan University of Economics and Law, Wuhan 430073, China \\ ${ }^{3}$ School of Foreign Language, Zhongnan University of Economics and Law, Wuhan 430073, China \\ Correspondence should be addressed to Weiqin Tang; twqing@163.com
}

Received 13 May 2014; Accepted 2 September 2014; Published 29 October 2014

Academic Editor: Ali R. Ashrafi

Copyright (C) 2014 Weiqin Tang et al. This is an open access article distributed under the Creative Commons Attribution License, which permits unrestricted use, distribution, and reproduction in any medium, provided the original work is properly cited.

\begin{abstract}
Since the "agriculture super-docking" mode was introduced in China in 2007, remarkable success has been made in reducing the transaction cost and improving the quality safety of agricultural products. However, the quality safety issues of agricultural products still occur frequently because both specialized farmers' cooperatives and supermarkets have insufficient safety investment. In order to study the necessity, goal, and incentive decision schemes of safety investment in "agriculture super-docking" supply chain, three kinds of models, which include noncooperatives distributed decision-making model, centralized decision-making model, and incentive coordination models led by cooperatives and supermarkets, are, respectively, set up in this paper. Conclusions are drawn as follows: when making the uncooperative decentralized decision, both cooperatives and supermarkets have the moral risks to decrease the safety investment, but appropriate measures can achieve the coordination of the supply chain; when achieving the coordination of supply chain, the two contacts under the guidance of cooperatives and supermarkets are the same, and the schemes of distributing profits are also the same. Moreover, a practical case is given to improve the effectiveness and feasibility of the incentive decision schemes.
\end{abstract}

\section{Introduction}

With the development of economy and the improvement of people's living standard, residents have paid more attention to the quality of consumer staples, especially agricultural products, and their quality safety has become an important index for consumers. The traditional agricultural products have to go through the dealers, distributors, retailers, and other links. The long channel often leads to a number of problems, such as information lag, severe circulation loss, and high transaction cost [1]. In order to reduce the circulation link, lower procurement costs, invigorate the circulation of agricultural products, stimulate rural consumption, and solve the contradiction between "difficult to sell agricultural products" and "difficult to buy agricultural products," some large supermarkets such as Zhongbai Storage, Wal-Mart, and Metro and other supermarkets, in the support of the Chinese Ministry of Commerce and the Chinese Ministry of agriculture in 2007, began to introduce the "agriculture super-docking" procurement mode. Later, the Ministry of Commerce, the Ministry of Finance, and the Ministry of Agriculture jointly issued a document to promote the direct cooperation between large supermarkets and specialized farmers' cooperatives and to strengthen the link between production and marketing. Till now, "agricultural superdocking" mode has achieved remarkable success in reducing the transaction cost, stabilizing prices, and resolving the contradictions between production and marketing. Supermarkets are starting to replace the traditional farmer's trade markets and have been integrated into the main channel for consumers to buy agricultural products. However, the quality safety issues still occur frequently because both cooperatives and supermarkets have no enough safety investment. Therefore, it is very important to investigate how to encourage the two major partners to increase safety investment to ensure the safety of agricultural products.

The existing literature about the safety problems of food supply chain mainly focused on the following two 
themes: one was the system and construction of government supervision and the other was the analysis of safety behavior of market main bodies. The study on system and construction of government supervision covered the laws, regulation systems and their efficiency $[2,3]$, the quality and safety standard system [4], and traceability system [5], and the study on the analysis of safety behavior of market main bodies covered suppliers' safety behaviors from the view of influence factor [6], mechanism and countermeasures of safety behaviors of supplier market [7], consumers' safety behavior from the view of influence factor [8], mechanism and efficiency of market behavior concerning food safety [9], the safety behavior from the view of influence factor of consumers' purchasing food [10], and the food safety cognition of consumer [11]. In addition, several scholars studied the problem of food supply chain from the perspective of safety investment. For example, Wang and Liu [12] made the game analysis on the safety problems of the food supply chain from the perspective of safety investment. Xu et al. [13] set up an evolutionary game model of suppliers and manufacturers' food quality investments, but they seemed to overlook the incentive problem in the supply chain.

Recently, a lot of efforts have been made to coordinate the supply chain of agricultural products. Pathumnakul et al. [14] researched coordination problems of shrimp supply chain in Thailand by using historical data to fit the growth function of shrimp. Xiao et al. [15] studied pricing strategy of seasonal products with many quality levels. For the purpose of controlling circulation loss, Chen et al. [16] analyzed multilevel discount pricing strategy of agricultural products in elasticity demand and nonhomogeneous sales period. By establishing the function of fresh degree, Chen and Dan [17] investigated the coordination mechanism of two-level supply chain concerning agricultural products including both physical and value loss. Based on the assumption that the disturbance of output and demand follows a uniform distribution, Zhao and $\mathrm{Wu}$ [18] designed a contract of sharing revenue which was helpful for improving the coordination of the two-level agricultural products' supply chain under the "origin-supermarkets" circulation mode. Lin et al. [19] emphasized a contract of sharing revenue on a three-level supply chain of fresh agricultural products under the mode of traditional circulation. The above literature aims at the problems of unilateral asymmetric information. Although these academic enquiries have contributed to the understanding of supply chain of agricultural products, they do not seem to be suitable for the incentive coordination problem of lateral asymmetrical information in "agriculture superdocking" supply chain.

In terms of "agriculture super-docking" mode, scholars have made qualitative and quantitative research. The qualitative studies mainly focused on development models [20, $21]$, problems, and countermeasures $[22,23]$. On the other hand, quantitative researches appeared to be more interested in the performance of supply chain $[24,25]$, distribution optimization [26], and cooperatives game [24, 27-29]. To understand the quality safety of agricultural products under "agriculture super-docking” supply chain, Li [30] put forward a number of countermeasures to realize the quality safety by examining the main market bodies in the process of production, circulation, consumption, and supervision of agricultural products in "agriculture super-docking." Further, Yu [31] carried out a comparative analysis on several main supply chains of agricultural products and argued that "agriculture super-docking" mode is one of the effective ways to improve the quality safety of agricultural products. Different from the two prior investigations, $\mathrm{Gu}$ et al. [32] and $\mathrm{Pu}$ et al. [33] analyzed how factors such as penalties degree, price incentive, and the cost of supermarkets detection have played a role on quality control. Based on the principal-agent theory, Fei [34] set up a model for the problem of farmers' participation and incentive constraint and analyzed it by applying Kuhn-Tucker condition, and further he proposed some suggestions in order to ensure that farmers provide the agricultural products of the high quality safety. $\operatorname{Li}[30,35]$ analyzed the multigame problem of two parties by using KMRW reputation model under the condition of the asymmetric information. From the perspective of quality control of supply chain, Cui and Pang [36] established an evolutionary game model between the retailer and supplier in "agriculture super-docking" mode by applying the method of evolutionary game theory and analyzed the evolution trend of strategy selection between the supermarkets and cooperatives. These studies have allowed for more opportunities to understand "agriculture superdocking" mode, but it seems to be lacking the fact that the incentive problems of supply chain were investigated from the perspective of safety investment in "agriculture superdocking" mode.

To sum up, the existing literature studied a number of the issues related to the food safety of supply chain, and less research was made from the perspective of safety investment to analyze the incentive coordination of agricultural products' supply chain and quality safety of agricultural products in "agriculture super-docking" mode. Moreover, much discussion mainly focused on the unilateral asymmetric information problem, and the study on the problem of bilateral asymmetry information was lacking. In fact, "agriculture superdocking" supply chain is composed of two different interest main parties, cooperatives and supermarkets, which tend to hide information and action in order to seek financial gains. In addition, the previous literature mostly supposed that the variables of demand function include the price of agricultural products and one party's effort cost of supply chain. In the paper, Douglas production function is introduced and demand quantities of agricultural products are assumed to be a function of the safety investment of both cooperatives and supermarkets at a certain level of price, income, and consumer preference. The following several parts tend to discuss the necessity, goal, and incentive decision mechanism of improving safety investment of cooperatives and supermarkets in "agriculture super-docking" supply chain. In Section 2, a basic problem is described. In Section 3, a noncooperative distributed decision-making model is set up and the necessity of incentive coordination decision-making is analyzed. In Section 4, a centralized decision model of complete information is created and the goal of the incentive coordination is analyzed. In Section 4, two incentive coordination models of supply chains led by cooperatives and 
supermarkets are, respectively, established, and the optimal decision schemes on safety investment of cooperatives and supermarkets incentive are pointed out. In Section 5, a specific case is applied. In Section 6, the conclusions of the full paper are made.

\section{Problem Description}

Consider a two-level supply chain that is consisted of a single specialized farmers' cooperative and a single supermarket. The supermarket directly purchases agricultural products from the cooperative. In order to improve the quality safety of agricultural products, the cooperative has to invest in improving quality safety technology, which is called cooperatives' safety investment, and the supermarket also has to make certain investments in detection of agricultural products, cold chain logistics, and preservation equipment, which is called safety investment of cooperatives. In addition to safety investment, the cooperative also needs production cost for the seeds' procurement, the payment of employees' salary, and so forth. The supermarket needs advertisement cost, facilities cost, and other sale costs.

If the price of agricultural products, consumers' income, and preference are fixed, the demand of market mainly depends on the quality safety degree of agricultural products and in turn on safety investment of supply chain. Therefore, the safety investments of cooperative and supermarket can be taken as variables which affect the market demand. Suppose the demand function of agricultural products is $q=$ $f\left(x_{1}, x_{2}\right)=k x_{1}{ }^{\alpha} x_{2}{ }^{\beta}$, where $\alpha, \beta$ stand for the demand's elasticity of safety investment of cooperative and supermarket, respectively, $0<\alpha<1,0<\beta<1, x_{1}, x_{2}$ denote the safety investments of cooperative and supermarket, respectively, and coefficient $k$ stands for a certain level of price, income, and consumers' preference. Unit production cost of the cooperative except for safety production cost is denoted as $c_{1}$, unit sale cost of the supermarket except for safety investment for sale is denoted as $c_{2}$, the sale price of agricultural products is denoted as $p$, the price of agricultural products which are provided from the cooperative to the supermarket is denoted as $p_{1}$, and the profits of the cooperative, the supermarket, and the whole supply chain system are denoted as $\pi_{1}, \pi_{2}$, and $\pi$, respectively.

The "agriculture super-docking" supply chain consists of a cooperative and a supermarket, whose interests are different. Thus, each party tends to hide information and to seek greater economic interests. At the same time, agricultural products as trusted products also lead to the asymmetry of information. Therefore, noncooperatives decentralized decision between the cooperative and supermarket formed. In this situation, the cooperative and supermarket do not reach an agreement on safety investment. In order to maximize their own profits, both will choose an optimal safety investment. Suppose the optimal safety investment of cooperative is denoted as $x_{1}{ }^{*}$ and the optimal safety investment of supermarket is denoted as $x_{2}{ }^{*}$.

In this case, profit function of the cooperative is as follows:

$$
\pi_{1}=\left(p_{1}-c_{1}\right) k x_{1}{ }^{\alpha} x_{2}{ }^{\beta}-x_{1} .
$$

The profit function of the supermarket is denoted as

$$
\pi_{2}=\left(p-p_{1}-c_{2}\right) k x_{1}{ }^{\alpha} x_{2}{ }^{\beta}-x_{2} .
$$

According to formula (1), the calculation was made for the first order partial derivative of function $\pi_{1}$ with respect to $x_{2}$, and the following formula can be reached:

$$
\frac{\partial \pi_{1}}{\partial x_{2}}=\beta\left(p_{1}-c_{1}\right) k x_{1}^{\alpha} x_{2}^{\beta-1} .
$$

In formula (3), because of the known conditions $p_{1} \geq c_{1}$, $k>0, x_{1}>0$, and $x_{2}>0$, the inequality $\partial \pi_{1} / \partial x_{2}>0$ can be deduced.

Thus, there is a positive correlation between the safety investment of supermarket and the profits of cooperative.

According to formula (2), the calculation is made for the first order partial derivative of the function $\pi_{2}$ with respect to $x_{1}$, and the following formula (4) can be obtained:

$$
\frac{\partial \pi_{2}}{\partial x_{1}}=\alpha\left(p-p_{1}-c_{2}\right) k x_{1}^{\alpha-1} x_{2}^{\beta}>0 .
$$

In formula (4), because of the known conditions $p-p_{1}-$ $c_{2}>0, k>0, x_{1}>0$, and $x_{2}>0$, we can deduce the inequality $\partial \pi_{2} / \partial x_{1}>0$.

Thus, there is a positive correlation between the safety investment of cooperative and the profits of supermarket.

Therefore, we can obtain Proposition 1.

Proposition 1. Both safety investments of the specialized farmers' cooperative and supermarket are positively correlated with each other's profits.

Proposition 1 shows that when the cooperative increases safety investment, the supermarket' profits will increase, and when supermarkets increase, so will the profits of cooperative.

According to formula (1), the calculation is made for the first order partial derivative of the function $\pi_{1}$ with respect to $x_{1}$, and the following formula can be reached:

$$
\frac{\partial \pi_{1}}{\partial x_{1}}=\left(p_{1}-c_{1}\right) k \alpha x_{1}^{\alpha-1} x_{2}^{\beta}-1 .
$$

According to formula (2), the calculation for the first order partial derivative of the function $\pi_{2}$ with respect to $x_{2}$ and the following formula can be obtained:

$$
\frac{\partial \pi_{2}}{\partial x_{2}}=\beta\left(p-p_{1}-c_{2}\right) k x_{2}{ }^{\alpha} x_{2}{ }^{\beta-1}-1 .
$$

Therefore, we can obtain Proposition 2.

Proposition 2. The cooperative or market's increasing its own safety investment in supply chain does not necessarily increase their own profits.

According to formula (5), $\partial \pi_{1} / \partial x_{1}$ is not necessarily greater than 0 ; that is to say, the cooperative does not necessarily increase its own profits by increasing its safety 
investment. According to formula (6), $\partial \pi_{2} / \partial x_{2}$ is not necessarily greater than 0 ; that is to say, the supermarket does not necessarily earn increased profits by increasing its own investment in safety.

According to Propositions 1 and 2, when only the cooperative increases the safety investment and the investments enhance the safety degree of agricultural products, its market demand will increase correspondingly. Thus, the supermarket will reap more profits because of its free-rider behaviors, but, for the cooperative, more profits may not be realized because of the increasing safety investment. It is the same for supermarkets. When only the supermarket increases safety investment and the investments improve the safety degree of agricultural products, their demand will increase. Thus, cooperatives will get more profits because of their free-rider behavior, but the supermarkets may not be able to get more profits because its safety investment increases. Therefore, when making decisions uncooperatively, both cooperative and supermarket have the moral risks of reducing safety investment. Supply chain coordination incentive is very important to avoid the impact of moral risk on the quality safety of agricultural products.

\section{Centralized Decision-Making Model under Complete Information of Supply Chain}

3.1. Setting Up and Solving the Model. When information is complete, the cooperative and the supermarket will reach a consensus on the safety investment. Under the centralized decision-making, the cooperative and the supermarket ally. Therefore, the goal of the model is to maximize profits of the overall supply chain. follows:

In this case, the profits of the overall supply chain are as

$$
\pi=\left(p_{1}-c_{1}-c_{2}\right) k x_{1}^{\alpha} x_{2}^{\beta}-x_{1}-x_{2} .
$$

According to formula (7), the calculation is made for the first order partial derivative of function $\pi$ with respect to variables $x_{1}, x_{2}$, respectively, and the outcomes are as follows:

$$
\begin{aligned}
& \frac{\partial \pi}{\partial x_{1}}=\alpha\left(p_{1}-c_{1}-c_{2}\right) k x_{1}{ }^{\alpha-1} x_{2}{ }^{\beta}-1, \\
& \frac{\partial \pi}{\partial x_{2}}=\beta\left(p_{1}-c_{1}-c_{2}\right) k x_{1}{ }^{\alpha} x_{2}{ }^{\beta-1}-1 .
\end{aligned}
$$

Let formula (8) be 0 ; the following formulas can be obtained:

$$
\begin{aligned}
& \alpha\left(p_{1}-c_{1}-c_{2}\right) k x_{1}{ }^{\alpha-1} x_{2}{ }^{\beta}-1=0, \\
& \beta\left(p_{1}-c_{1}-c_{2}\right) k x_{1}{ }^{\alpha} x_{2}{ }^{\beta-1}-1=0 .
\end{aligned}
$$

Solve the set of the formulas, and the optimal investment of the cooperative is as follows:

$$
x_{1}^{*}=\left[k \alpha^{1-\beta} \beta^{\beta}\left(p_{1}-c_{1}-c_{2}\right)\right]^{1 /(1-\alpha-\beta)} .
$$

The optimal investment of the supermarket is denoted as

$$
x_{2}^{*}=\left[k \alpha^{1-\alpha} \beta^{\alpha}\left(p_{1}-c_{1}-c_{2}\right)\right]^{1 /(1-\alpha-\beta)} .
$$

The optimal profits of supply chain are expressed as

$$
\begin{aligned}
\pi^{*}= & {\left[k\left(p_{1}-c_{1}-c_{2}\right)\right]^{1 /(1-\alpha-\beta)} \alpha^{(\alpha+\beta+\alpha \beta) /(1-\alpha-\beta)} \beta^{2 \alpha \beta /(1-\alpha-\beta)} } \\
& -\left[k \alpha^{1-\beta} \beta^{\beta}\left(p_{1}-c_{1}-c_{2}\right)\right]^{1 /(1-\alpha-\beta)} \\
& -\left[k \alpha^{1-\alpha} \beta^{\alpha}\left(p_{1}-c_{1}-c_{2}\right)\right]^{1 /(1-\alpha-\beta)} .
\end{aligned}
$$

Proposition 3. When decisions under complete information are made, the maximized profits of supply chain can be reached.

Proof. Suppose

$$
f\left(x_{1}, x_{2}\right)=\pi=\left(p_{1}-c_{1}-c_{2}\right) k x_{1}{ }^{\alpha} x_{2}{ }^{\beta}-x_{1}-x_{2} .
$$

In formula (13), the calculation is made for the second order partial derivative of function $f\left(x_{1}, x_{2}\right)$ with respect to $x_{1}$ and $x_{2}$ and the following formula (14) can be obtained:

$$
\begin{aligned}
& \frac{\partial^{2} f}{\partial x_{1}{ }^{2}}=\alpha(\alpha-1)\left(p_{1}-c_{1}-c_{2}\right) k x_{1}{ }^{\alpha-2} x_{2}{ }^{\beta} \\
& \frac{\partial^{2} f}{\partial x_{2}{ }^{2}}=\beta(\beta-1)\left(p_{1}-c_{1}-c_{2}\right) k x_{1}{ }^{\alpha} x_{2}{ }^{\beta-2} .
\end{aligned}
$$

Because of the known conditions $0 \prec \alpha \prec 1$ and $0 \prec \beta \prec$ 1 , the set of inequalities $\partial^{2} f / \partial x_{1}{ }^{2} \prec 0, \partial^{2} f / \partial x_{2}{ }^{2} \prec 0$ can be acquired. Therefore, $f\left(x_{1}, x_{2}\right)$ is a concave function of safety investment $x_{1}$ of the cooperative. Namely, when $\partial f / \partial x_{1}=0$, a uniquely optimal solution $\left(x_{1}{ }^{* *}, x_{2}{ }^{* *}\right)$ of safety investment exists, which can satisfy

$$
\max \pi=\left(p_{1}-c_{1}-c_{2}\right) k x_{1}^{* * \alpha} x_{2}^{* * \beta}-x_{1}{ }^{* *}-x_{2}{ }^{* *}
$$

Thus, $x_{1}{ }^{* *}, x_{2}{ }^{* *}$ are the maximum extreme point of $f\left(x_{1}, x_{2}\right)$, at which the profits of supply chain will be maximized.

3.2. Goal of Supply Chain's Incentive Coordination. Under the decentralized decision-making, both cooperative and supermarket will have the moral risk of reducing safety investment. An incentive coordination between cooperative and supermarket is very important in order to increase the profits of the overall supply chain system.

It can be inferred from Proposition 3 that coordination's goal of supply chain is to ensure safety investment of the cooperative and the supermarket to reach the level under complete information. Accordingly, the system's profits also reach the level under complete information. 


\section{Incentive Coordination Model}

4.1. Incentive Coordination Model under the Guidance of Cooperation. In the supply chain led by the specialized farmers' cooperative, the safety investment of supermarket is unobservable and thus cannot be verified.

The main task of cooperative is to design appropriate contracts in order to encourage the supermarket to increase safety investment and to eliminate moral risk. The safety investment of supermarket will be entirely consistent with its optimal investment of the overall supply chain under complete information.

In this case, the cooperative is facing the following optimal problem:

$$
\begin{aligned}
P_{1}: \max & \pi_{1}=\left(p_{1}-c_{1}\right) k x_{1}{ }^{\alpha} x_{2}{ }^{\beta}-x_{1} \\
& x_{1}=\arg \max \pi_{2} \\
\text { s.t. } \quad & x_{2}=\arg \max \pi_{2} \\
& \pi_{2} \geq 0 .
\end{aligned}
$$

As long as the cooperative designs an appropriate contract $p_{1}{ }^{*}$, which can follow formula (17), the above programme can be solved. Consider

$$
\pi_{2}=\lambda \pi, \quad \lambda \in[0,1] .
$$

Then, the optimal decisions of the cooperative are as follows:

$$
\frac{\partial \pi_{2}}{\partial x_{1}}=\lambda \frac{\partial \pi}{\partial x_{1}}, \quad \frac{\partial \pi_{2}}{\partial x_{2}}=\lambda \frac{\partial \pi}{\partial x_{2}}
$$

In this case, the optimal decisions of supermarket are exactly the same as those in centralized decision-making under complete information. At the same time, the profits of cooperative are expressed as

$$
\pi_{1}=(1-\lambda) \pi, \quad \lambda \in[0,1] .
$$

The optimal decision of the cooperative is expressed as

$$
\begin{aligned}
& \frac{\partial \pi_{1}}{\partial x_{1}}=(1-\lambda) \frac{\partial \pi}{\partial x_{1}} \\
& \frac{\partial \pi_{1}}{\partial x_{2}}=(1-\lambda) \frac{\partial \pi}{\partial x_{2}} .
\end{aligned}
$$

The above formulas show that, in the supply chain led by cooperative, the cooperative can also reach the maximal decision result under the premise that the outcome of independent decision-making of the supermarket is consistent with that of decision-making of overall supply chain.

Therefore, the following formula can be obtained from formula (17):

$$
\begin{aligned}
(p & \left.-p_{1}{ }^{*}-c_{2}\right) k x_{1}{ }^{\alpha} x_{2}{ }^{\beta}-x_{2} \\
& =\lambda\left[\left(p-c_{1}-c_{2}\right) k x_{1}{ }^{\alpha} x_{2}{ }^{\beta}-x_{1}-x_{2}\right] .
\end{aligned}
$$

The specific form of $p_{1}{ }^{*}$ is as follows:

$p_{1}{ }^{*}=\frac{\lambda x_{1}+(\lambda-1) x_{2}-\left(\lambda p-\lambda c_{1}-\lambda c_{2}+c_{2}-p\right) k x_{1}{ }^{\alpha} x_{2}{ }^{\beta}}{k x_{1}{ }^{\alpha} x_{2}{ }^{\beta}}$.

Proposition 4 can be deduced from formula (22).

Proposition 4. In the "agriculture super-docking" supply chain led by cooperative, when the cooperative provides the contract such as

$p_{1}^{*}=\frac{\lambda x_{1}+(\lambda-1) x_{2}-\left(\lambda p-\lambda c_{1}-\lambda c_{2}+c_{2}-p\right) k x_{1}{ }^{\alpha} x_{2}{ }^{\beta}}{k x_{1}{ }^{\alpha} x_{2}{ }^{\beta}}$,

the overall supply chain will achieve coordination.

In short, in the supply chain led by cooperative, although the cooperative cannot scrutinize the safety investment of supermarket and thus cannot write the supermarket' safety investment requirements into the contract, it can provide a contract like formula (22) for the supermarket to be selected in order to achieve coordination of the supply chain. Contract parameter $\lambda$ belongs to an arbitrary value of range $[0,1]$.

4.2. Incentive Coordination Model under the Guidance of Supermarket. In the supply chain led by supermarket, the safety investment of cooperative is unobservable and cannot be verified.

The main task of the supermarket is to design appropriate contracts in order to promote the cooperative to increase safety investment and eliminate moral risk. Safety investment of cooperative will be entirely consistent with its optimal investment of the overall supply chain centralized decisionmaking under complete information.

In this case, the supermarket is facing the following optimal problem:

$$
\begin{aligned}
P_{2}: \max & \pi_{2}=\left(p-p_{1}-c_{2}\right) k x_{1}{ }^{\alpha} x_{2}{ }^{\beta}-x_{2} \\
x_{1} & =\arg \max \pi_{1} \\
\text { s.t. } \quad x_{2} & =\arg \max \pi_{1} \\
& \pi_{1} \geq 0 .
\end{aligned}
$$

As long as the supermarket designs an appropriate contract $p_{1}{ }^{*}$, which can follow formula (25), the above programme can be solved. Consider

$$
\pi_{1}=\phi \pi, \quad \phi \in[0,1] .
$$
follows:

Then, the optimal decisions of the cooperative are as

$$
\frac{\partial \pi_{1}}{\partial x_{1}}=\phi \frac{\partial \pi}{\partial x_{1}}, \quad \frac{\partial \pi_{1}}{\partial x_{2}}=\phi \frac{\partial \pi}{\partial x_{2}}
$$

In this case, the optimal decisions of the cooperative are exactly the same as those in centralized decision-making under complete information. 
At the same time, the profits of supermarket are denoted as

$$
\pi_{2}=(1-\phi) \pi, \quad \phi \in[0,1]
$$

The optimal decision of supermarket is expressed as

$$
\begin{aligned}
& \frac{\partial \pi_{2}}{\partial x_{1}}=(1-\phi) \frac{\partial \pi}{\partial x_{1}} \\
& \frac{\partial \pi_{2}}{\partial x_{2}}=(1-\phi) \frac{\partial \pi}{\partial x_{2}} .
\end{aligned}
$$

The above formulas show that, in the supply chain led by supermarket, the supermarket can also achieve the optimal decision result under the premise that the outcome of independent decision-making of the cooperative is consistent with the overall decision-making of supply chain.

Therefore, the following formula can be obtained from formula (25):

$$
\begin{aligned}
& \left(p_{1}{ }^{* *}-c_{1}\right) k x_{1}{ }^{\alpha} x_{2}{ }^{\beta}-x_{1} \\
& \quad=\phi\left[\left(p-c_{1}-c_{2}\right) k x_{1}{ }^{\alpha} x_{2}{ }^{\beta}-x_{1}-x_{2}\right] .
\end{aligned}
$$

The specific form of $p_{1}{ }^{* *}$ is as follows:

$$
p_{1}{ }^{* *}=\frac{\left(\phi p-\phi c_{1}-\phi c_{2}\right) k x_{1}{ }^{\alpha} x_{2}{ }^{\beta}-(\phi-1) x_{1}-\phi x_{2}}{k x_{1}{ }^{\alpha} x_{2}{ }^{\beta}} \text {. }
$$

Proposition 5 can be shown from formula (30).

Proposition 5. In the "agriculture super-docking" supply chain led by the supermarket, when the supermarket provides the contract such as

$$
p_{1}{ }^{* *}=\frac{\left(\phi p-\phi c_{1}-\phi c_{2}\right) k x_{1}{ }^{\alpha} x_{2}{ }^{\beta}-(\phi-1) x_{1}-\phi x_{2}}{k x_{1}{ }^{\alpha} x_{2}{ }^{\beta}},
$$

the overall supply chain will achieve coordination.

In short, in the "agriculture super-docking" supply chain led by the supermarket, although the supermarket cannot supervise the safety investment of cooperative and thus cannot write the cooperative safety investment requirements into the contract, it can provide a contract like formula (30) for the cooperative to be selected in order to achieve coordination of the supply chain. Contract parameter $\phi$ belongs to an arbitrary value of range $[0,1]$.

Proposition 6. When the contractual parameters meet $\lambda+\phi=1, p_{1}{ }^{*}=p_{1}{ }^{* *}$ can be reached.

Proof. The expression $\lambda=1-\phi$ can be obtained from the expression of $\lambda+\phi=1$.

Substituting it into formula (22), the outcome is as follows:

$$
p_{1}{ }^{*}=\frac{\left(\phi p-\phi c_{1}-\phi c_{2}\right) k x_{1}{ }^{\alpha} x_{2}{ }^{\beta}-(\phi-1) x_{1}-\phi x_{2}}{k x_{1}{ }^{\alpha} x_{2}{ }^{\beta}}=p_{2}{ }^{*} \text {. }
$$

Then the conclusion is proved.
TABLE 1: Outcomes in the incentive model under the guidance of the cooperative.

\begin{tabular}{lcccccc}
\hline$\pi_{1}$ & $\pi_{2}$ & $\pi$ & $\lambda$ & $p_{1}$ & $x_{1}{ }^{*}$ & $x_{2}{ }^{*}$ \\
\hline 17.55 & 11.7 & 29.25 & 0.4 & 6.36 & 146.25 & 116.98 \\
14.625 & 14.625 & 29.25 & 0.5 & 6.3 & 146.25 & 116.98 \\
11.7 & 17.55 & 29.25 & 0.6 & 6.24 & 146.25 & 116.98 \\
8.775 & 20.475 & 29.25 & 0.7 & 6.18 & 146.25 & 116.98 \\
\hline
\end{tabular}

TABLE 2: Outcomes in the incentive model under the guidance of the supermarket.

\begin{tabular}{lcccccc}
\hline$\pi_{1}$ & $\pi_{2}$ & $\pi$ & $\phi$ & $p_{1}$ & $x_{1}{ }^{*}$ & $x_{2}{ }^{*}$ \\
\hline 8.775 & 20.475 & 29.25 & 0.3 & 6.18 & 146.25 & 116.98 \\
11.7 & 17.55 & 29.25 & 0.4 & 6.24 & 146.25 & 116.98 \\
14.625 & 14.625 & 29.25 & 0.5 & 6.3 & 146.25 & 116.98 \\
17.55 & 11.7 & 29.25 & 0.6 & 6.36 & 146.25 & 116.98 \\
\hline
\end{tabular}

Proposition 6 shows that no matter whether the incentive is under the guidance of supermarket or cooperative, the supply chain can achieve coordination. When the supply chain achieves coordination, the two contracts are the same and their schemes of profits' distribution are also the same.

\section{A Decision-Making Example of Incentive Coordination}

In this section, a decision-making example of the incentive coordination is given to show how to apply our incentive decision-making model.

Suppose that the market price of a kind of agricultural product is 10 , the demand's elasticity $\alpha$ of safety investment of cooperative is 0.5 , the demand's elasticity $\beta$ of safety investment of supermarket is 0.4 , coefficient $k$ is 0.6 , and unit production cost $c_{1}$ of agricultural products, unit sale $\operatorname{cost} c_{2}$ of agricultural products, and their sale price are 3, 1 , and 10, respectively. According to the prior formulas, it can be obtained that, in the centralized decision-making of supply chain under complete information, the optimal safety investment of the cooperative is 146.25 , the optimal safety investment of supermarket is 116.98, and the profits are 29.25.

In the incentive coordination model under the guidance of supermarkets, when the supply chain achieves incentive coordination, its calculated outcomes are listed in Table 1.

In the incentive coordination model under the guidance of the cooperative, when the supply chain achieves incentive coordination, its calculated outcomes are listed in Table 2.

From the tables, it can be inferred that, in the supply chain under the guidance of cooperative, the profits of cooperative and supermarket depend heavily on the value of $\lambda$ when the supply chain achieves coordination. The higher the value of $\lambda$, the higher the profits assigned to the supermarket and the lower the contract price $p_{1}$ from the cooperative to the supermarket. However, in the supply chain under the guidance of the supermarket, the profits of the cooperative and market rely on the value of $\phi$ when the supply chain achieves coordination. The higher the value of $\phi$, the higher 
the profits assigned to the cooperative and the lower the contract price $p_{1}$ from the cooperative to the supermarket. In addition, when the contractual parameters meet the expression $\lambda+\phi=1$, the two contracts are the same and so are their schemes of profit distribution. We can also know that the optimal safety investment of cooperative is 146.25 , the optimal safety investment of supermarket is 116.98 , and the profits are 29.25 .

\section{Conclusions}

In this paper, three kinds of models, which include noncooperatives distributed decision-making model, centralized decision-making model, and incentive coordination models led by cooperatives and supermarket, are set up in order to, respectively, study the necessity, goal, and decision schemes of incentives of safety investment in "agriculture superdocking" supply chain. Conclusions are as follows.

(1) When the uncooperative decentralized decision is made, the safety investment of one party in supply chain can lead to the profit increase of the other party, but it does not necessarily lead to the increase of its own profits. Therefore, both cooperative and supermarket have the moral risks to decrease the safety investment. In order to avoid the impact of moral risks on the quality safety of agricultural products, the incentive coordination of supply chain is especially important.

(2) When the centralized decision-making under complete information is made, the chain can maximize profits. Therefore, the goal on the incentive coordination of supply chain is that the safety investment of cooperative and supermarket can reach the level of centralizing decision-making under complete information. At the same time, the profits of the whole system can also reach the level of centralized decision-making under complete information.

(3) In a supply chain led either by cooperative or by market, although the cooperative or market cannot supervise the safety investment of the supermarket and thus cannot write its safety investment requirements into the contract, it can provide a contract for the other side to be selected in order to achieve coordination of the supply chain.

(4) When the coordination of the supply chain is achieved, the forms of the contacts under the guidance of the cooperative and the supermarket are the same and so are the profit distribution's schemes.

In addition, we apply our incentive decision-making design to a specific application. The results show that the decision-making design is simple and operable and has good application value.

\section{Conflict of Interests}

The authors declare that there is no conflict of interests regarding the publication of this paper.

\section{Acknowledgments}

This project is supported by the 2011 Key Subject of National Social Science Foundation of China (no. 11AGL006), the 2013 Natural Science Foundation of Hubei Province, China (no. 2013CKB013), and the 2014 Ministry of Education of Humanities and Social Science Project (no. 14YJAZH071).

\section{References}

[1] J. Chen and B. Dan, "Some loss issuses of fresh agricultural items in circulation and corresponding policies," Modernization of Management, vol. 4, pp. 19-21, 2008.

[2] W. Alex, "International food safety regulation in the United States and the European union-balancing confidence and trade, discussion," American Journal of Agricultural Economics, vol. 91, no. 5, pp. 1491-1492, 2009.

[3] T. Yasuda, "Food safety regulation in the United States : an empirical and theoretical examination," Independent Review, vol. 15, no. 2, pp. 201-226, 2010.

[4] A. Hultberg, M. Schermann, and C. Tong, "Results from a mail survey to assess Minnesota vegetable growers' adherence to good agricultural practices," HortTechnology, vol. 22, no. 1, pp. 83-88, 2012.

[5] M. Thakur, C.-F. Sørensen, F. O. Bjørnson, E. Forås, and C. R. Hurburgh, "Managing food traceability information using EPCIS framework," Journal of Food Engineering, vol. 103, no. 4, pp. 417-433, 2011.

[6] C. R. Doss, "Designing agricultural technology for African women farmers: lessons from 25 years of experience," World Development, vol. 29, no. 12, pp. 2075-2092, 2001.

[7] P. C. Abhilash and N. Singh, "Pesticide use and application: an Indian scenario," Journal of Hazardous Materials, vol. 165, no. 1-3, pp. 1-12, 2009.

[8] J. M. Antle, "No such thing as a free safe lunch: the cost of food safety regulation in the meat industry," The American Journal of Agricultural Economics, vol. 82, no. 2, pp. 310-322, 2000.

[9] R. Smith, Produce Industry Has Responsibility for Food Safety, Southwest Farm Press, 2011.

[10] R. J. Signs, V. L. Darcey, T. A. Carney, A. A. Evans, and J. J. Quinlan, "Retail food safety risks for populations of different races, ethnicities, and income levels," Journal of Food Protection, vol. 74, no. 10, pp. 1717-1723, 2011.

[11] L. X. Zhang and L. L. Han, "An analysis on consumer perception of safe food and purchase behavior-a survey of Fresh food in Shanghai," Chinese Agricultural Science Bulletin, vol. 25, no. 4, pp. 50-54, 2009.

[12] Y. F. Wang and Y. X. Liu, "Game analysis on product safety input of food supply chain," Journal of Northwest A \& F University, vol. 38, no. 3, pp. 155-159, 2010.

[13] M. L. Xu, Q. Wang, and L. H. Ouyang, "Investment decision of food supply chain quality based on the evolutionary game," Chinese Journal of Management Science, vol. 20, no. 5, pp. 131141, 2012.

[14] S. Pathumnakul, K. Piewthongngam, and S. Khamjan, "Integrating a shrimp-growth function, farming skills information, and a supply allocation algorithm to manage the shrimp supply chain," Computers and Electronics in Agriculture, vol. 66, no. 1, pp. 93-105, 2009.

[15] Y. B. Xiao, P. Wu, and Y. L. Wang, "Pricing strategies for fresh products with multiple quality levels based on customer choice behavior," Chinese Journal of Management Science, vol. 18, no. 1, pp. 58-65, 2010. 
[16] J. Chen, B. Dan, and X. M. Zhang, "EOQ model for fresh agricultural product under progressive price discount and losscontrolling," System Engineering Theory and Practice, vol. 29, no. 7, pp. 43-54, 2009.

[17] J. Chen and B. Dan, "Fresh agricultural product supply chain coordination under the physical loss-controlling," System Engineering Theory and Practice, vol. 29, no. 3, pp. 54-62, 2009.

[18] X. Zhao and F. Wu, "Coordination of agri-food chain with revenue-sharing contract under stochastic output and stochastic demand," Chinese Journal of Management Science, vol. 17, no. 5, pp. 88-95, 2009.

[19] L. Lin, S. P. Yang, and B. Dan, "Three-level supply chain coordination of fresh and live agricultural products by revenuesharing contracts," Journal of Systems Engineering, vol. 25, no. 4, pp. 484-492, 2010.

[20] P. Moustier, P. T. G. Tam, D. T. Anh, V. T. Binh, and N. T. T. Loc, "The role of farmer organizations in supplying supermarkets with quality food in Vietnam," Food Policy, vol. 35, no. 1, pp. 69-78, 2010.

[21] Q. Zhou, "New circulation mode of agricultural built by 'agriculture super-docking,' Contemporary Economy, vol. 5, pp. 8-10, 2012.

[22] Z. H. Zhou and H. B. Guo, "The supply chain optimization of agricultural product, present situation and countermeasure of 'agriculture super-docking,' Logistics SCI TECH, vol. 8, pp. 2123, 2013.

[23] F. Cassia, M. Ugolini, and A. Bonfanti, "The perceptions of Italian farmers' market shoppers and strategic directions for customer-company-territory interaction," Procedia -Social and Behavioral Science, vol. 58, pp. 1008-1017, 2012.

[24] X. J. Pu, Q. Y. Zhu, and W. B. Cao, "Research on the Governance Model of farmer-supermarket direct-purchase supply chain \& the incentive for Specific investment," Journal of South China Agricultural University, vol. 12, no. 1, pp. 85-92, 2013.

[25] B. Pritchard, C. P. Gracy, and M. Godwin, "The impacts of supermarket procurement on farming communities in India: evidence from rural Karnataka," Development Policy Review, vol. 28, no. 4, pp. 435-456, 2010.

[26] J. Wang, Q. Jia, and H. X. Yang, "Study on third party joint distribution and cost amortization in 'agriculture superdocking,' Logistics Technology, vol. 32, no. 7, pp. 4-9, 2013.

[27] X. J. Pu and W. B. Cao, "Cooperation mechanism of alliance of agricultural and supermarkets, the analysis frame of spatial Duopsony model," Chinese Journal of Management, vol. 9, no. 10, pp. 1543-1547, 2012.

[28] L. Liu, Z. Qiao, and C. Liu, "A cooperation game in the model of connection agricultural with supermarkets," Journal of Industrial Engineering/Engineering Management, vol. 26, no. 4, pp. 100-106, 2012.

[29] X. J. Pu, L. Lu, and L. Jiang, "How certain factors influence the efficient alliance between agriculture and supermarkets?" Journal of South China Agricultural University (Social Science Edition), vol. 12, no. 4, pp. 27-34, 2013.

[30] Y. Li, "Game analysis of KMRW reputation model in supply chain farmland-supermarkets docking," Logistics Technology, vol. 32, no. 5, pp. 400-402, 2013.

[31] L. Yu, "Supply chain safety management of agricultural products in 'agriculture super-docking', Henan Agricultural, vol. 1, pp. 26-27, 2014.

[32] C. Gu, Y. F. An, and C. Liu, "Study on quality control in the model of "agriculture super-docking"', Soft Science, vol. 25, no. 6, pp. 21-24, 2011.
[33] X. J. Pu, L. Jiang, and H. M. Liu, "Quality control policy and the choice of organization pattern in alliance of agriculture and supermarkets," Journal of Beijing Institute of Technology, vol. 14, no. 3, pp. 51-55, 2012.

[34] W. Fei, "Research on principal-agent problem in the alliance of agriculture and supermarkets, taking the quality and safety of agricultural products as an example," Journal of South China Agricultural University, vol. 12, no. 1, pp. 93-99, 2013.

[35] Z. Li, "Study on safety problem of agricultural products in 'agriculture super-docking,' Social Science of Gansu, vol. 2, pp. 233-237, 2013.

[36] L. Cui and S. Pang, "Evolutionary game analysis on retailersupplier relationship in linkage between farmers and supermarkets based on supply chain quality control," Journal of Beijing Technology and Business University (Social Sciences), vol. 28, no. 5, pp. 48-54, 2013. 


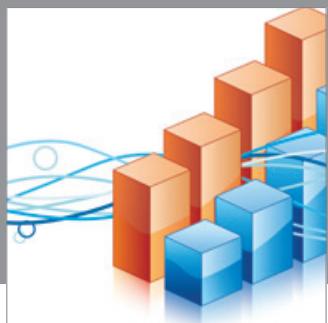

Advances in

Operations Research

mansans

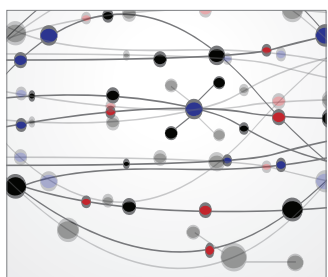

The Scientific World Journal
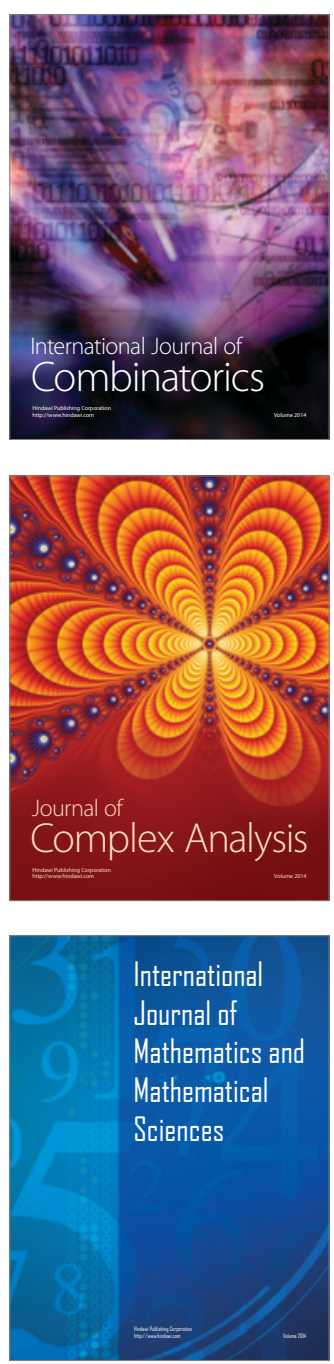
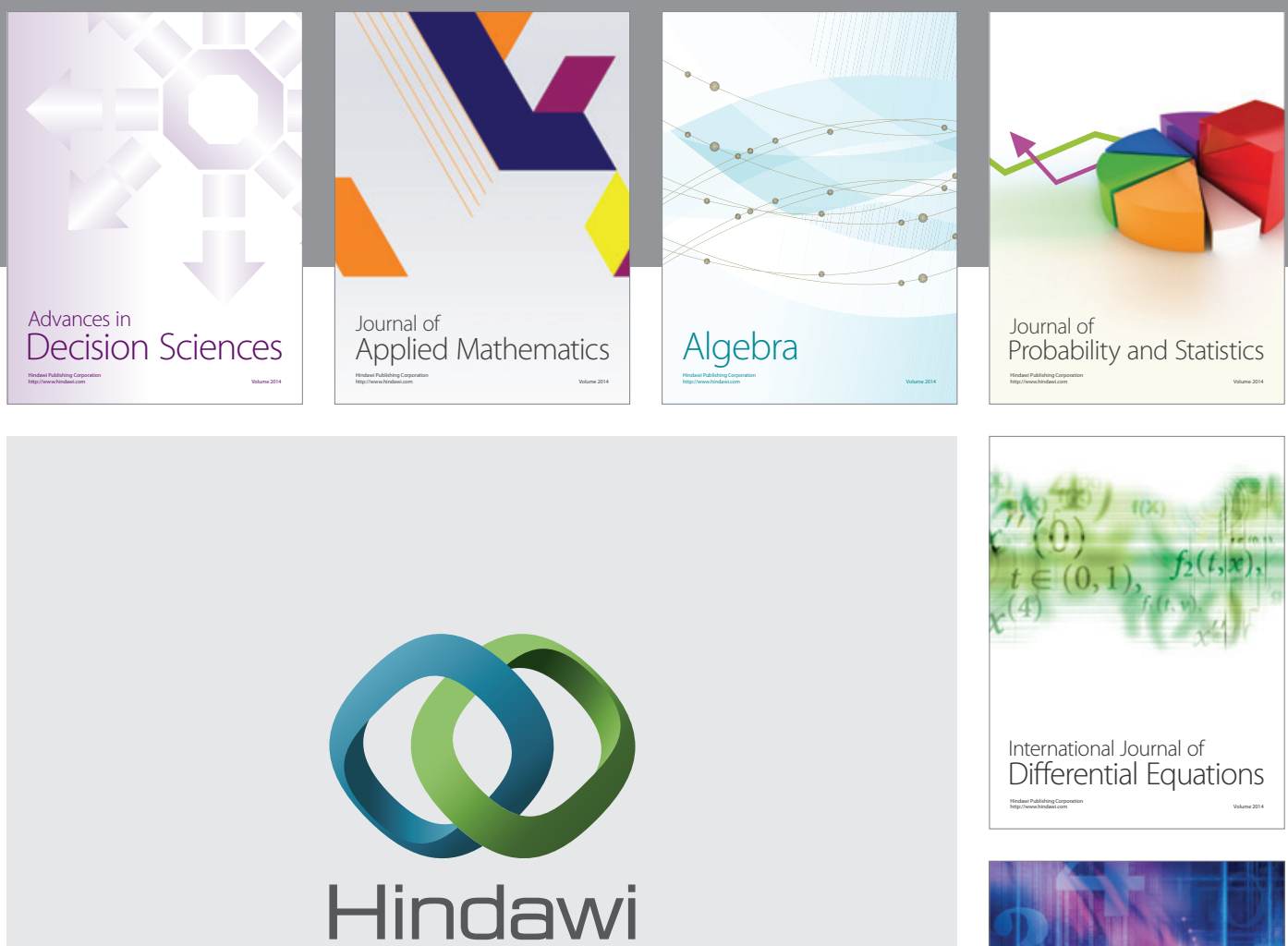

Submit your manuscripts at http://www.hindawi.com
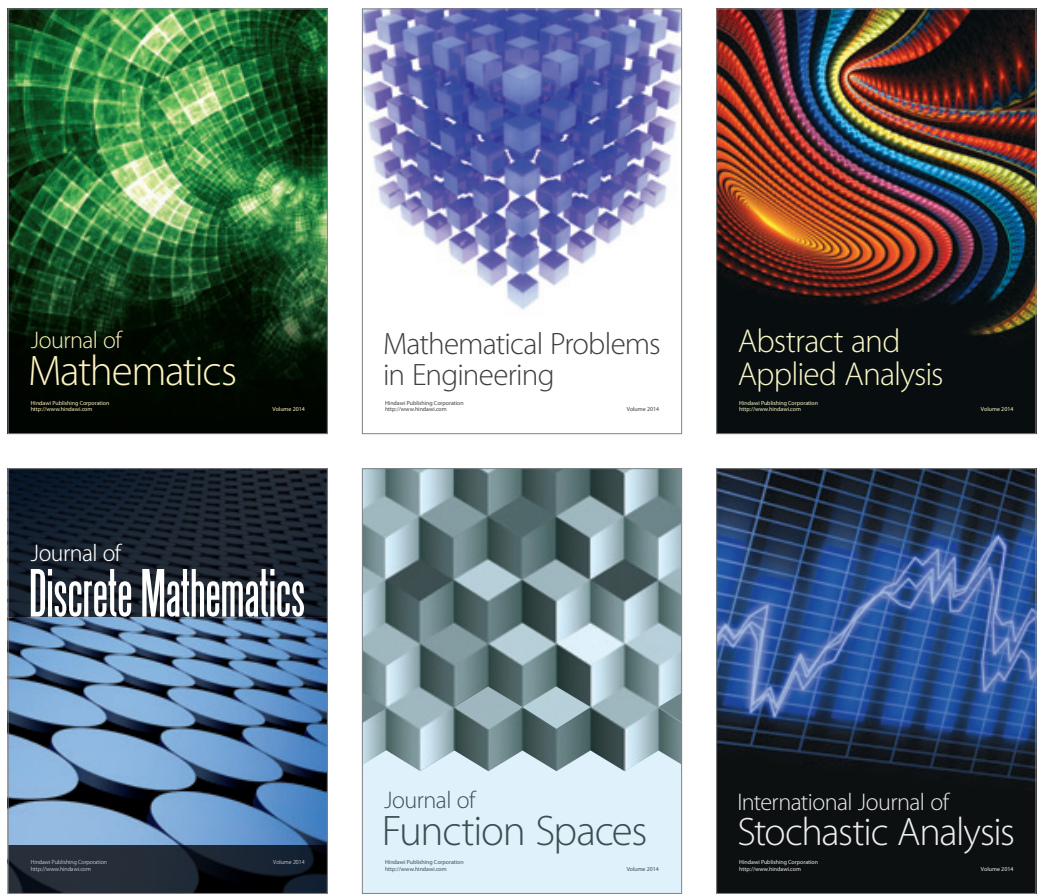

Journal of

Function Spaces

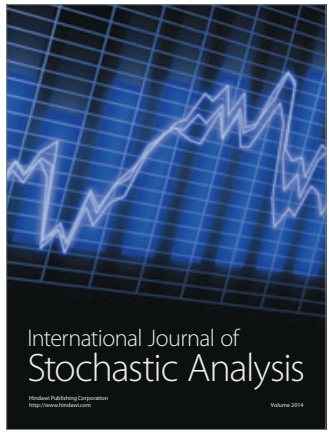

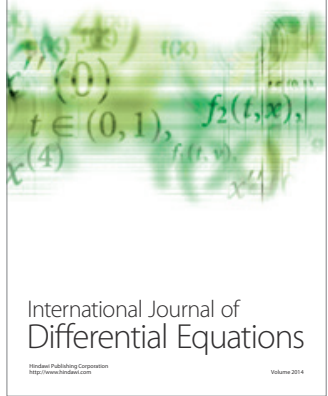
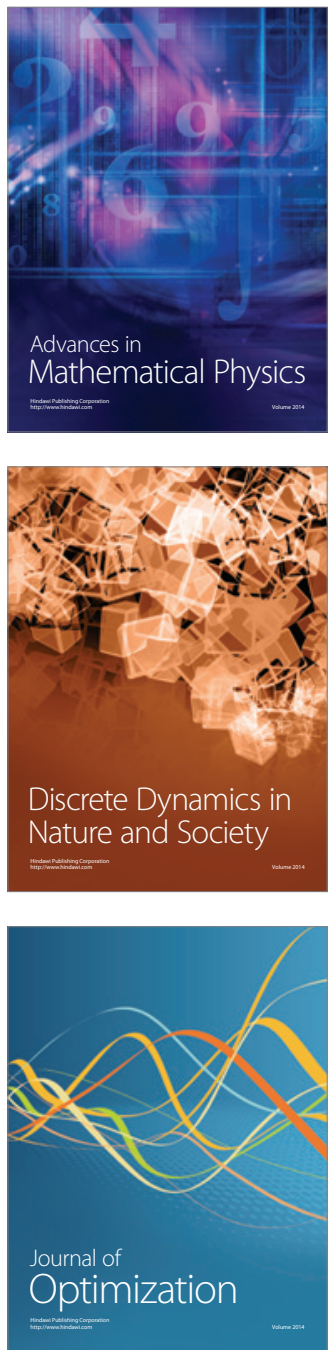